\title{
Estratégias editoriais, enciclopedismo, produtos e publicidade na revista Educação Physica $(1932-1945)^{1}$
}

Omar Schneider* Amarílio Ferreira Neto**

Resumo: discute a fórmula editorial da revista Educação Physica, periódico sobre Educação Física, esportes e saúde que circulou entre os anos de 1932 a 1945 na cidade do Rio de Janeiro. Analisa o aparelho crítico do impresso, prestando atenção aos dispositivos editoriais empregados pelos editores para maior controle sobre os modos de manipulação e usos da Revista. Aborda o periódico como enciclopédia e estande de produtos e publicidade.

Palavras-chave: Revista Educação Physica, Dispositivos, Fórmula Editorial.

Roger Chartier (2004, p. 275), ao discutir a fórmula editorial de um conjunto de livros produzidos na França, entre os séculos XVII e XVIII, denominados de livros de cordel, os quais compõem a Bibliothèque bleue, discorre que é "[...] a fórmula editorial que dá ao objecto formas próprias". * Doutorando em Educação no Programa de Estudos Pós-Graduados em Educação História, Política, Sociedade da Pontifícia Universidade Católica de São Paulo.
Membro do Instituto de Pesquisa em Educação e Educação Física (PROTEORIA)

** Doutor em Educação pela Universidade Metodista de Piracicaba e professor do Centro de Educação Física e Desportos da Universidade Federal do Espírito Santo. Coordenador do PROTEORIA.

1 O estudo faz parte da dissertação defendida em 2003, no Programa de Estudos Pós-Graduados em Educaça: História, Política, Sociedade da Pontifícia Universidade Católica de São Paulo, com o título A Revista Educação Physica (1932-1945): estratégias editoriais e prescrições educacionais.

2 Ao aplicar ao estudo do periódico a perspectiva desenvolvida por Chartier, tem-se que fazer alguns esclarecimentos. Entre eles, o de que tal enfoque é destinado pelo autor à análise de projetos editoriais que se consubstanciam em forma de livros. A mesma advertência realiza Barzotto (1998, p. 46), ao enfocar a questão em sua tese de doutoramento sobre a revista Realidade. De acordo com o autor, utilizar as proposições de Chartier para o estudo das revistas periódicas exige uma certa cautela pois "[ de Chartier para o [.] Chartier descreve [...] procedimentos tendo em vista a impressão de livros [...] [porquanto] num primeiro momento, é necessário supor que os limites da ação dos trabalhadore da imprensa no processo de produção de revistas periódicas podem ser diferentes daqueles que se estabelecem para o caso da impressão de livros".

Movimento, Porto Alegre, v. 10, n. 3, p.23-52, setembro/dezembro de 2004 
Para Chartier (1994, p. 16), não se devem “[...] ignorar os processos através dos quais um texto faz sentido para aqueles que o lêem". Justamente as operações pelas quais os editores organizam e dão a ler o impresso apresentam-se como parte de sua arquitetura, ou seja, as opções que são feitas pelos editores para tornar o impresso legível e coerente, de acordo com o ponto de vista que desejam imprimir ao impresso.

Ainda conforme Chartier (1994, p. 17)

[...] contra a representação [...] segundoa qualo texto existeem simesmo, isolado de toda a materialidade - deve selembrarquenão há texto fora do suportequeo dáa ler (ouvir), esublinharofatode quenão existe a compreensão de um texto, qualquer que seja, que não dependa das formas através das quais ele atinge o seu leitor.

Estudar as operações e os modos de organizar o texto para produzir uma leitura adequada é, para Toledo (2001), fundamental para a compreensão de um projeto editorial. Toledo (2001), ao estudar a Coleção Atualidades Pedagógicas, trabalha com tal hipótese, chamando esse procedimento de estudo do aparelho crítico. ${ }^{3}$ Conforme Toledo (2001, p. 4), o aparelho crítico "[...] tem como função ou a didatização da obra ou uma sofisticação de sua apresentação [...] na qual está inserida uma proposta especifica, que orienta o leitor para uma determinada forma [...]" de se apropriar do conteúdo do impresso ou do conjunto ao qual ele pertence. De acordo com a autora, trabalhar

[...] na perspectiva da História Cultural, adotada por Oliveiro [autora que utiliza comouma de suas referências], não sópossibilita a reconstrução histórica das práticas específicas desenvolvidas pelos editores, como também permite redesenhar os leitores visados por essas práticas, os leitores imaginados e construídos pela prática editorial (TOLEDO, 2001, p.4).

O objetivo do estudo é analisar o aparelho crítico da revista Educação Physica, "[...] desenvolvendo a hipótese de que tais elementos são, como o próprio conteúdo [...] [veiculado] fundamentais para a compreensão de um projeto editorial" (TOLEDO, 2001, p. 149). Desse modo, o estudo coloca-se como uma possibilidade à tendência de estudar o mundo dos impressos valorizando apenas o seu conteúdo, ou seja, uma leitura que se prende aos discursos veiculados, aos tipos de discursos e às relações entre eles.

3 Assim como as proposições de Chartier (1990 e 1994) em relação à História do Livro são utilizadas com algumas ressalvas no estudo da imprensa periódica especializada, o mesmo procedimento deve ser feito em relação às proposições de Toledo (2001), pois o objeto ao qual a autora direciona seu olhar é outro, a história das coleções, possuindo, desse modo, outras características e outra lógica de composição.

Movimento, Porto Alegre, v. 10, n. 3, p.23-52, setembro/dezembro de 2004 
A metodologia amparada pela História Cultural utiliza as proposições que apresentam como possibilidade "[...] uma arqueologia dos objetos [...], [a qual procura] apanhá-los na sua forma, sua freqüência, seu dispositivo [e] sua estrutura" (NUNES; CARVALHO,1993, p. 45). Projetar o objeto em termos de uma arqueologia, de acordo com Carvalho (1998, p. 4), “[...] implica tratar o impresso a ser analisado como objeto cultural que, constitutivamente, guarda as marcas de sua produção e de seus usos". ${ }^{4}$

\section{Apresentação material da Revista}

A revista Educação Physica foi produzida no Rio de Janeiro, por iniciativa de dois professores de Educação Física, Paulo Lotufo (editor no período de 1932 a 1945) e Oswaldo Murgel Rezende (editor no período de 1932 a 1944). Posteriormente a esses dois editores, somamse mais dois, Roland de Souza (editor no período de 1936 a 1941), e Hollanda Loyola (editor no período de 1939 a 1944).

Nos treze anos em que o periódico circulou, foram lançadas 88 revistas. Dessas, dois exemplares foram publicados em edições conjugadas em um mesmo volume, a de número 28/29 e a de número $79 / 80$. No inventário que foi produzido do impresso, foi possível catalogar $3.768^{5}$ matérias, sendo 1.566 assinadas por 805 autores diferentes.

Na publicação do seu primeiro número, a Revista foi intitulada como Educação Physica: Revista Téchnica de Esportes e Athletismo (1932). A partir do lançamento do décimo terceiro número (dezembro de 1937), passa a se chamar Educação Physica: Revista Technica de Esportes e Saúde. No número seguinte (janeiro de 1938), o termo técnica é suprimido, passando o periódico a ser impresso como Educação Physica: Revista de Esportes e Saúde. Em 1939, no número 28/29, seguindo as orientações da reforma ortográfica de 1937, passa a ser grafada como Educação Física: Revista de Esportes e Saúde, assim apresentada até a publicação de seu último número, no ano de 1945.

4 Tratando sobre o uso da Arqueologia e seu instrumental teórico no campo da História, Schnapp (1988, p. 4) discute que "[...] a forma indica a destinação, [e que] Historia, Schnapp (1988, p. 4) discute que "[...] a forma indica a destinação, [e que]
o modo de fabricação indica uma certa organização [...]", assim, os testemunhos o modo de fabricação indica uma certa organização [...]", assim, os testemunhos
residuais de uma cultura correspondem à materialidade e à formalidade das residuais de uma cultura correspondem à materialidade
práticas produzidas pela sociedade da qual é originária.

5 Nesse total está incluído tudo que foi publicado durante o período em que a Revista circulou.

Movimento, Porto Alegre, v. 10, n. 3, p.23-52, setembro/dezembro de 2004 
No período em que a revista Educação Physica esteve em circulação, ela não modificou suas dimensões. Durante os treze anos em que foi impressa, foi produzida medindo $27,5 \mathrm{~cm}$ de altura por $20 \mathrm{~cm}$ de largura.

A Figura 1, a seguir, representa o ritmo de publicação do impresso e sua periodicidade. ${ }^{6}$

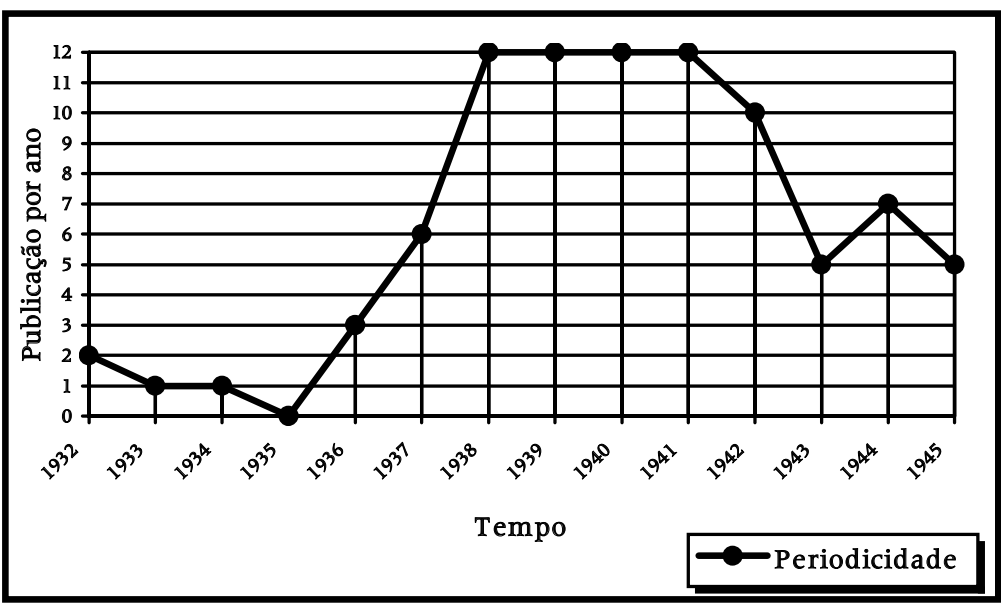

Figura 1. Ritmo de produção da revista Educação Physica (1932-1945)

Com base na análise do ritmo do impresso, foi possível constatar dois períodos subdivididos em duas fases cada um. O primeiro período (1932 a 1938), dividido entre 1932 a 1934, como uma fase de nascimento em que o projeto da Revista está sendo produzido, e de 1936 a 1938, fase caracterizada por uma curva ascendente. No segundo período (1938 a 1945), assim como no anterior, podem-se perceber duas fases, uma de 1938 a 1941, momento em que o impresso passa a lançar doze exemplares ao ano, caracterizando-se como um momento de grande estabilidade do projeto editorial, e a outra de 1942 a 1945, em que o periódico diminui o ritmo de producão, a qual é demarcada por uma curva descendente, uma tentativa de reação e o fim da publicação.

6 O emprego do termo periodicidade no estudo, referindo-se ao campo editorial, deve ser entendido como o período previsto entre edições sucessivas de um mesmo tipo de publicação, ou como a regularidade do ritmo de produção de uma série e as causas suscetíveis de explicá-la no campo da História.

7 Em 1935 a Revista sofre uma paralisação, para voltar a circular somente em 1936.

Movimento, Porto Alegre, v. 10, n. 3, p.23-52, setembro/dezembro de 2004 


\section{As capas}

Como o local em que o leitor tem o primeiro contato com o impresso, as capas são muito importantes na constituição de um padrão gráfico. Lugar de reconhecimento, as capas revelam ao leitor antecipadamente o que é a Revista, sem que a tenha que folhear. Na produção da fórmula editorial do impresso, investimentos são feitos em relação à sua capa para que ela se torne mais atraente aos leitores.

De 1932 a 1937, a composição da capa da revista Educação Physica possui elementos que a diferenciam dos utilizados nos anos posteriores. Precisamente da Revista número l até a Revista número 14, o arranjo da capa possui um nível maior de elaboração. O primeiro fator a chamar a atenção diz respeito ao uso das cores. Nos primeiros cinco anos, o layout é produzido utilizando uma gama muito variada de tons, a feitura das capas em sua maior parte recebe um maior acabamento, o uso de gravuras é feito de forma mais intensa e o fundo das imagens é produzido em perspectiva.

O título da Revista do número 1 ao 10 é impresso em tipos manuscritos $^{8}$ na parte superior da capa, o centro é dedicado à reprodução de uma gravura em que pessoas em grupo ou individualmente estão praticando algum esporte. Nas primeiras cinco Revistas, a parte inferior da capa é utilizada para informar aos leitores quais são as leituras que serão veiculadas no periódico. ${ }^{9}$

Fato que marca os primeiros cinco anos da Revista é a dificuldade de se estabelecer um padrão. O layout, a cada número lançado, sofre algumas modificações, como a disposição dos elementos que o compõem (imagens, número do exemplar e ano de publicação) e os tipos utilizados para apresentar o conteúdo do impresso. Somente após o lançamento do décimo primeiro número é que se começa a estabelecer um padrão mais constante. O modelo que se propõe para a capa do exemplar número 11 , pelas várias facilidades de composição que oferece, será adotado e maior constância terá na veiculação do impresso.

8 Os termos técnicos utilizados para descrever a composição da revista Educação Physica foram empregados segundo as orientações do Manual do Tipógrafo (1948), Phy autoria de Ralph W. Polk para a organizaç̃o dos Mantontos nógrafo (1948), de autoria de Ralph W. Polk, para a organização dos elementos necessários para uma boa disposição das informações que são fixadas no material impresso. Para
maior detalhamento, ver o capítulo XXII sobre a Classificação dos tipos.

9 Parte do que é tratado na Revista é antecipadamente explicitado ao leitor, sem que tenha que recorrer ao seu Índice.

Movimento, Porto Alegre, v. 10, n. 3, p.23-52, setembro/dezembro de 2004 
Diferente das anteriores, a capa da Revista número 11 (1937) é produzida com um layout que agrega poucos elementos e se torna o modelo mais utilizado para compor a apresentação externa do impresso. É um modelo menos rico em detalhes. Sua composição traz poucas informações a respeito do que o leitor encontrará no interior do impresso, o uso de cores para produzir a capa também diminui ela no máximo passa a ser produzida utilizando quatro cores: uma que serve de fundo e outras que irão compor a gravura, que tanto pode ser imagens de deuses e deusas do panteon grego, como de atletas expoentes do desporto no Brasil. Nesse modelo de capa, o título da Revista é impresso em tipos maiúsculos romanos, o ano e o número do periódico ganham maior destaque e, pela primeira vez, informa-se aos leitores, abaixo do seu nome, que o impresso é uma revista técnica de esportes. ${ }^{10}$

O layout que é adotado na Revista número 11 vai ser utilizado até o exemplar de número 27 (1939). As quatro Revistas seguintes $(28 / 29,30,31$ e 32$)$ são lançadas com outro modelo. Agora o nome do periódico é impresso com as iniciais em tipos romanos em maiúsculas e o restante em tipos grifados em minúsculas, identificando, logo abaixo do seu título que ela é uma revista de esportes e saúde. A imagem que ornamenta a capa e o número da publicação passam a ser centralizados, assim como a indicação do ano, porém estes últimos em sua parte inferior. ${ }^{11}$

Após a publicação da Revista número 32, volta-se a adotar o modelo de composição que tinha vigorado até o exemplar número 27. Somente em 1943, outra tentativa de mudança do design da capa é realizada, mas, do mesmo modo que a tentativa feita entre os números $28 / 29$ e 32 , essa também dura pouco tempo, unicamente nos exemplares de número 73, 74 e 75.

O modelo adotado a partir do Revista número 32 continua a apresentar o título em tipos romanos em maiúsculas, mas deixa-se de fazer referência na capa que ela é uma revista de esportes e saúde. Passa-se a imprimir o número e ano na parte superior e abaixo do nome do impresso, ao mesmo tempo em que se começa a fazer menção que ela possui publicação mensal. Interessante é que, nesse ano, a Revista perde sua periodicidade mensal e passa a ser publicada bimestralmente. Após a publicação do exemplar número 75, a capa

10 Antes do lançamento do número 11 (1937), essas informações eram veiculadas somente na parte superior da página em que o índice das matérias eram impressos. 11 Com a mudança do modelo de composição da capa, muda-se também o modo de se grafar a Revista, que passa a ser impressa como Educação Física, e não mais como Educação Physica.

Movimento, Porto Alegre, v. 10, n. 3, p.23-52, setembro/dezembro de 2004 
da Revista volta a apresentar o design anterior com algumas pequenas modificações, entre elas: a referência de que o periódico possui uma publicação mensal é deslocada para a lateral do layout. Logo abaixo, volta-se a mencionar que ela é uma revista de esportes e saúde. Pela primeira vez, aparece na capa o mês de publicação. ${ }^{12}$

A última modificação que é introduzida em relação à composição da capa se verifica no formato dos tipos utilizados para imprimir o nome do periódico, mas que é incluída apenas nos três exemplares finais do impresso $(76,77$ e 78) em 1945. Nesses exemplares, o título é impresso em maiúsculas grifadas, em preto, com as iniciais de EDUCAÇÃO FÍSICA na cor branca.

No processo de produção de um padrão gráfico para a capa da Revista, o modelo mais utilizado foi o inaugurado com a publicação do exemplar de número 11 (1937). Nele estão registradas as modificações que por mais tempo são mantidas. O nome da Revista ganhou mais destaque que as gravuras e fotos veiculadas. O nome passou a ser impresso na cor branca com uma sombra ao fundo, o que causa a ilusão de que o título está se projetando da superfície do papel. O subtítulo, quando aparece, é menor que o nome e em cor preta, fazendo com que o título se torne mais destacado, configurandose como a grande identificação do impresso.

O uso de cores só foi empregado de forma mais intensa na composição das capas nos seus primeiros cinco anos de existência. No interior da Revista, o uso de cores foi muito moderado. Quando utilizado, era feito com a aplicação de apenas um clichê vermelho ou azul.

A partir de 1938 (Revista número 15), o modelo adotado permite a produção da cobertura externa do impresso de forma mais rápida. Trocando apenas a cor de fundo e a gravura ou a imagem que vai compor o layout, tem-se uma nova capa. Essa facilidade de composição faz com que esse modelo seja o mais utilizado pelos editores.

As imagens que são veiculadas nas capas da Revista eram mais um atrativo para sua aquisição. Elas representam um desencadear de sentidos que permite aos editores, a partir da elaboração do padrão gráfico das capas, dizer aos leitores do que se trata o impresso. Os editores buscam persuadir os leitores a adquirir o impresso pela exposição de corpos em movimento, homens e mulheres felizes e engajados na busca de desenvolver um corpo belo, perfeito e de linhas bem definidas.

12 A referência de que o impresso é uma publicação mensal é veiculada na capa até o último número produzido.

Movimento, Porto Alegre, v. 10, n. 3, p.23-52, setembro/dezembro de 2004 
As imagens veiculadas nas capas, tanto as que são gravuras de pessoas praticando esportes, quanto fotografias dos deuses e deusas do panteon grego e esportistas em ação, são reproduzidas como o exemplo do cultivo do corpo e adestramento/aperfeiçoamento das energias corpóreas.

De modo geral, a produção das capas, a partir do lançamento da Revista número 14 (1938), passou a visar mais à criação de um padrão de identificação para o impresso do que a criação de um novo layout para cada novo exemplar publicado, além de, com a criação de uma uniformidade em relação ao design da apresentação exterior do impresso, haver tanto a diminuição dos custos para a sua produção, como a possibilidade de criar o sentido de uma coleção.

A padronização do processo de composição dos elementos que formam a capa do impresso produz a sua identidade visual, criando, desse modo, a idéia de uma coleção estável. Nesse processo, tem-se a possibilidade de economizar em tempo de fabricação e investimentos de recursos financeiros, mas também de homogeneizar a produção do impresso. Com a adição ou supressão de poucos elementos (como imagens ou a cor de fundo), tem-se uma nova capa.

\section{As matérias dadas a ler}

A revista Educação Physica, ao longo do período em que foi produzida, apresenta um modo de organizar as matérias que não é peculiar somente a ela, faz parte da estratégia da indústria dos impressos para tentar didatizar e/ou sofisticar a apresentação do material que é colocado em circulação por meio de dispositivos editoriais.

Em seu primeiro exemplar, informa-se na capa que esse número é dedicado ao ensino da Technica do Basket Ball. Nas próximas Revistas, não mais se trabalhará com uma temática central, mas o periódico passará a tratar da vulgarização de vários esportes e seu ensino técnico, assim como dos conhecimentos que compreendem serem os necessários para a formação/boa atuação do professor de Educação Física.

No Índice do primeiro número publicado, não há indicação da localização das matérias que são veiculadas. Das trinta matérias veiculadas nesse número, apenas quinze são apresentadas no Índice. Mesmo algumas das matérias que foram publicadas indicando a autoria não estão lá relacionadas. O Índice do primeiro número possui mais a função de apresentar a temática do periódico do que indicar ao leitor o lugar em que as matérias seriam veiculadas no interior do impresso.

Movimento, Porto Alegre, v. 10, n. 3, p.23-52, setembro/dezembro de 2004 
Na publicação dos números 2 (1932) e 3 (1933), a Revista é lançada sem a preocupação de dividir as matérias em grupos ou temas. O Índice desses dois exemplares é produzido de acordo com a ordem em que as matérias são distribuídas dentro do impresso. À frente do título da matéria e do nome do seu autor, imprime-se a página em que o leitor poderia localizar o assunto dentro do periódico.

A partir do lançamento do quarto número (1934), modifica-se o modo de apresentar as matérias no Índice. Elas passam a ser organizadas com base em elementos que as aproximam. As matérias são agrupadas sob um título que passa a indicar a qual grupo de discussão elas pertencem, assim o Índice perde a ordem de numeração crescente que apresenta até a terceira Revista e começa a ser apresentado em blocos segundo uma tipologia desenvolvida pelos editores. ${ }^{13}$ Desse modo, matérias que são impressas nas páginas finais ou iniciais podem ser organizadas e dadas a ler como pertencentes a um mesmo conjunto de textos.

Para classificar as matérias e dá-las a ler como pertencentes a um mesmo conjunto temático, os editores produzem alguns títulos a partir dos quais buscam chamar a atenção dos leitores para determinados assuntos. O resultado de organizar o índice da Revista desse modo é a produção de 63 títulos diferentes, alguns com vida efêmera, outros se constituindo como verdadeiros eixos condutores do impresso. A ação de agrupar textos sob um mesmo título é estratégia utilizada largamente pelos editores, pois, com tal movimento de agrupar as matérias no índice, movimenta-se a própria forma da Revista, regrando seus modos de manipulação, ou seja, a maneira como o impresso deveria ser consultado/lido.

Dispositivo de regramento da leitura, o modelo de Índice que é produzido ao se agrupar as matérias sob um determinado título homogeneíza o modo como a Revista deveria ser manipulada, o que facilita ao leitor a sua utilização, pois agrupar temas comuns sob um mesmo título constitui-se como estratégia de controle, tanto da leitura como da ordem em que as matérias deveriam ser lidas. ${ }^{14}$

$13 \mathrm{~A}$ ordenação dos títulos dos blocos de temas no Índice das matérias é feita em ordem alfabética durante todo o período em que esse dispositivo editorial utilizado.

140 dispositivo editorial designado como Índice só não é utilizado nos primeiros dois anos de circulação da Revista, momento em que se está traçando seu projet editorial, na edição de número 14 , nos números $74,75,76$ e 83 , assim como nas Revistas números 81 e 82, quando o impresso é publicado sem o índice das matérias.

Movimento, Porto Alegre, v. 10, n. 3, p.23-52, setembro/dezembro de 2004 
Agrupar em blocos os temas que tratam do mesmo assunto, ou assuntos próximos, pelo menos no Índice, tem como objetivo produzir certa coerência ao que é publicado e ordenar de forma didática a leitura das matérias. Organizar a leitura da Revista a partir do seu Índice tem dupla função: uma é a de indicar ao leitor o que ele encontrará no interior do impresso; a outra é fornecer a ele um roteiro no qual possa localizar os temas de seu interesse. A organização feita por assuntos permite aos editores produzir um índice que funciona como um roteiro de leitura, lugar em que os leitores são antecipadamente informados do modo como o impresso deve ser lido/manuseado.

No impresso, as matérias não estão agrupadas em blocos de assuntos; elas estão distribuídas por entre suas páginas, não apresentando conexão aparente, a não ser a que é proposta pelos editores por meio do Índice que se produz, por isso tal dispositivo materializa o roteiro de localização e leitura do que é veiculado.

O ordenamento que é dado às matérias, no interior da Revista, segue a prática editorial de otimizar ao máximo o espaço disponível do material impresso. Nesse sentido, a ocupação das páginas é feita entre a publicação de matérias relacionadas com a Educação Física e esportes, a venda de espaço publicitário e a utilização de recursos gráficos, como as imagens enviadas pelos leitores de alguma atividade esportiva que tenha ocorrido em sua escola ou clube, fotos de eventos esportivos acontecidos no Brasil e em outros países e gravuras/charges sobre a vida esportiva na cidade.

O problema da ocupação do espaço no interior do impresso é em parte solucionado com a adoção do recurso de continuar uma matéria em outra parte da Revista. Por exemplo, a publicação de um texto de Rui Barbosa, no exemplar de número 44 (1940), intitulado: Conceito e importância da educação física. Essa matéria se inicia nas páginas 10-12, tem continuidade na página 66 e só termina de ser veiculada nas páginas 72-73 do mesmo número Outro exemplo é o texto escrito pelo Dr. Hélio Vecchio Maurício, com o título: A Educação Física e suas vantagens, publicado no exemplar número 48 (1940), iniciado na página 31, é interrompido na página 32, para ser retomado somente na página 64 da mesma Revista.

A operação editorial empregada para a composição do periódico pode ser resultante de um imperativo básico para a sobrevivência de um projeto editorial, a necessidade de não deixar nenhum espaço em branco dentro de um impresso. De acordo com Andrade (1978), o papel é um item importante na apreciação do custo de produção de um material impresso. Conforme o autor (1978, p. 31), “[...] o papel

Movimento, Porto Alegre, v. 10, n. 3, p.23-52, setembro/dezembro de 2004 
para o livro representa quase uma quarta parte do seu custo final". ${ }^{15}$ Desse modo, na busca de preencher os espaços em branco que pudessem surgir no momento de compor o periódico, os editores produzem uma outra maneira para o seu manuseio. A leitura de parte da matéria publicada em um lugar tem à indicação de continua, conduzindo a leitura a outra página.

\section{O índice das matérias publicadas}

Ao estudar os dispositivos editoriais da Revista focando a atenção no modo como os editores trabalhavam o aparelho crítico do impresso, é possível compreender a forma de manipulação que paulatinamente os editores vão lhe imprimindo. Na tentativa de obter maior controle sobre os usos que dele serão feitos, um outro recurso entra em cena. A partir do ano de 1938, passa-se a publicar anualmente uma lista que inclui todas as matérias veiculadas durante o ano. Denominado pelos editores como Índice geral das matérias publicadas, ${ }^{16}$ esse recurso é impresso nas últimas páginas da última Revista produzida durante o ano.

o Índice geral das matérias publicadas, como o nome diz, era composto por todas as matérias veiculadas durante o ano. Ele era dividido por temas segundo uma tipologia desenvolvida pelos editores. Desse modo, as matérias eram organizadas levando em conta o assunto sobre o qual ela tratava.

As listas das matérias eram compostas da seguinte forma: sob um título (que poderia ser o nome de um esporte) uma tripla coluna

\footnotetext{
15 Andrade (1978) escreve tendo em vista a indústria do livro no Brasil. Pelo menos em relação às despesas do papel, acredito que possa utilizar as reflexões do autor em relaçã às despesas do papel, acredito que possa utilizar as reflexôes do autor para pensar os custos de produção do periódico. O autor, quando faz essa afirmação, está discutindo a produção de livros na década de 1970 no Brasil, período em que essa indústria já se encontra bem estruturada. No início da década de 1930 e meados da década de 1940, período em que a Revista circula, os custos relativos ao papel para a produção dos impressos eram bem maiores. Em primeiro lugar, em decorrência da crise econômica mundial vivida em fins da década de 1920 e primeiros anos da década de 1930. Depois, em função das dificuldades de importação de papel por causa da II Guerra Mundial (HALLEWELL, 1985). Sobre as dificuldades por que passou o setor editorial no Brasil nas décadas de 1930 e 1940, os editores do periódico assim relatam: "[...] quase todos os periódicos - jornais e revistas -" estão enfrentando dificuldades para se manterem circulando" (EDUCAÇÃO FÍSICA, 1944, n. 79/80, p. 5).

16 Os índices eram divulgados no mês de dezembro, porquanto somente na última 6 Os índices eram divulgados no mês de dezembro, porquanto somente na última
Revista impressa se poderia redigir a lista. A veiculação da lista só não ocorreu no ano de 1944. A relação (Índice) de matérias que deveria ser impressa em 1944 foi veiculada tão-somente na Revista correspondente ao mês de janeiro/fevereiro de 1945.
}

Movimento, Porto Alegre, v. 10, n. 3, p.23-52, setembro/dezembro de 2004 
trazia o nome da matéria à esquerda; a seguir, o número da Revista; e à direita o número da página em que o assunto havia sido tratado.

A tipologia que os editores escolhem para apresentar o Índice geral das matérias publicadas é a mesma utilizada para se produzir o Índice das matérias (sumário) da Revista. Desse modo, pode-se considerar que, na produção de sua fórmula editorial, os editores desenvolvem pelo menos três formas de organizar a leitura/utilização do impresso. Uma é o Índice das matérias, outra é o Índice geral das matérias publicadas, e a outra é o artifício dos Índices dos annuncios, o qual será discutido mais à frente, isso sem contar com as referências que são feitas nas capas sobre o conteúdo das Revistas até a publicação do exemplar número 6 (1936).

A veiculação do Índice geral das matérias publicadas passa a ser feita no momento em que os editores começam a produzir um novo sentido para a Revista.

A partir do número 19 (1938), passa-se a proporcionar o volume encadernado da revista Educação Physica para possíveis colecionadores e a oferecer o serviço de encadernação das coleções particulares. Desse momento em diante, o impresso passa a ser identificado como uma enciclopédia.

\title{
A revista como enciclopédia
}

De modo progressivo, a Revista vai se identificando como uma coleção. Passa a prescrever aos leitores a necessidade de se organizar os números publicados em volumes para que fosse garantida a sua preservação ao manuseio. Ao cabo de cada semestre, a Revista era organizada em um volume, de modo que pudesse ser acondicionada em uma estante e tomasse parte ao lado de outras obras. Conforme os editores, com a encadernação do impresso poderia se ter a

\begin{abstract}
[...] mais bela e mais completa coletânea de artigos técnicos, doutrinários, científicos [...], única no gênero no Brasil. É uma rica enciclopédia ilustrada indispensável ao manuseio de todos os que se dedicam aos esportes, à educação física e aos problemas da saúde (EDUCAÇÃO FÍSICA, 1940, n. 38, p. 76).
\end{abstract}

A estratégia editorial que passa a nortear a organização das Revistas publicadas faz com que elas sejam percebidas como uma enciclopédia em que os títulos atribuídos aos grupos de matérias funcionam como verbetes. Aliado a esse tipo de dispositivo, o aconselhamento de encadernar o periódico realmente faz com que a Revista materialize a idéia de uma enciclopédia, uma obra que reúne 
os conhecimentos produzidos sobre um domínio do saber, seguindo um critério de apresentação alfabético ou temático, fugindo, desse modo, da classificação aplicada aos impressos periódicos, pois a nova apresentação da Revista passa a ser feita em forma de tomos, o que permite que ela adquira um novo status. ${ }^{17}$

À medida que assume mais uma nova forma de manipulação, o impresso também apresenta um novo tipo de circulação. Agora ela não é apenas a Revista que pode ser levada para os passeios e locais públicos. O periódico passa a ser produzido como um objeto que vai compor uma biblioteca e por isso requer novo meio de manipulação, pois passa a ser restrita a ambientes privados e públicos que requerem certas condições de consulta. Situação que faz com que perca a condição de impresso efêmero, que apresenta ciclo de vida curto, para dilatar no tempo suas possibilidades de uso, uma vez que, ao ser encadernado, torna-se mais resistente à manipulação.

Nas visitas aos acervos ${ }^{18}$ que possuem exemplares da revista Educação Physica, foi constatado que muitas das coleções estão encadernadas em forma de volumes, sendo, desse modo, designadas nas etiquetas de identificação. Ao que parece, encadernar as revistas tornou-se prática normal, pois muitos dos acervos das bibliotecas são provenientes de doações de colecionadores particulares.

Em nota designada: Para ser um bom professor de Educação Física, os editores informam que o educador que quisesse ser considerado um bom professor, deveria "[...] estar sempre em dia com os múltiplos aspectos do seu magistério [...] e para isso [...] [seria] necessário comprar todos os livros que forem publicados nos mais variados idiomas [...], [e fazer] assinatura de revistas" (EDUCAÇÃO FÍSICA, 17 Conforme Barzotto (1998), ao encadernar uma revista, ela adquire novas características, as quais torna o periódico algo bem próximo ao livro. Para o autor (1998, p. 60), "[...] à revista interessa esse caráter de livro, desde que o veículo não se descaracterize enquanto revista. Que o leitor [...] considere [a revista] como livro é uma vantagem para a editora, uma vez que isso atesta o seu grau de importância [...], [que ultrapassa] o tempo vivido pelo leitor".

18 Em levantamento preliminar, foi possível localizar a revista Educação Physica nos seguintes acervos: Fundação Biblioteca Nacional (RJ) 1937-1945 (5-12, 1488); Biblioteca da Escola de Educação Física do Exército (RJ) 1932-1942 (1, 8-11, 16, 20, 21, 24-33, 37-60, 63-70); Biblioteca da UFRJ/CCS/BC (RJ) 1936-43 (7, 13, $15,17,21,24,26-63,65-88)$; Biblioteca da UNESP/BPP (SP) 1939-42 (26-39, $11,46-$ 15, 17, 21, 24, 26-63, 65-88); Biblioteca da UNESP/BPP (SP) 1939-42 (26-39, 41, 4647, 50, 56, 66); 1945 (88); Biblioteca da UNICAMP/FEF (SP) 1932-1945 (1-8, 10-22, 24-73, 75-80, 83-88); Centro de Memória da Educação Física e Esportes da Escola de Educação Física da UFRGS (RS) 1932-1945 (1-88); Associação dos Professores de Educação Física do Estado de São Paulo (APEF) 1936-1945 (5-55, 63-68, $70,72,73,74,78 / 80,88)$ e Biblioteca da Escola de Educação Física, Fisioterapia e Terapia educacional da UFMG (MG) 1936-1943 (6-13, 26-37, 71, 74, 76).

Movimento, Porto Alegre, v. 10, n. 3, p.23-52, setembro/dezembro de 2004 
1943, n. 72, p. 6). Mas, como nem todos os professores tinham essas condições, propõe-se que todos passassem a assinar a revista Educação Physica, pois essa se apresentava como uma "[...] síntese e uma seleção de tudo que [...] [havia] de mais moderno sobre educação física e desportos no Brasil e no mundo. É, pois, um dever de cultura e de honestidade profissional para o professor de educação física assinar e ler 'Educação Física' - por excelência a sua revista" (EDUCAÇÃO FÍSICA, 1943, n. 72, p. 6).

O professor de Educação Física era um dos destinatários previstos para a Revista, gênero de leitura pelo qual ele poderia estar a par do que de mais moderno estava sendo produzido e utilizado no Brasil e no mundo, lugar em que poderia ter contato com saberes pedagógicos, conhecer práticas pedagógicas experimentadas em outros locais do País e do exterior.

Os usos prescritos para a Revista indiciam para os seus destinatários os modos de apreensão do que era tido como o conhecimento essencial ao exercício da docência. O leitor, ao qual se busca educar o gosto e indicar os meios de obter, armazenar e utilizar os conhecimentos difundidos pela Revista, é projetado para o impresso.

As prescrições sobre o uso da Revista, aliadas ao dispositivo editorial do Índice geral das matérias publicadas, constituem parte da fórmula editorial desenvolvida para o periódico, revelando a inventividade e inovação com que foi sendo produzido o impresso, metamorfoseando diferentes formas para atrair e constituir um público leitor capaz de tornar-se potencialmente fiel à Revista por meio do hábito de colecionar, encadernar e dispor o material em uma biblioteca.

Biccas (2001, p. 109), escrevendo sobre a Revista de Ensino e seus modos de manipulação, discute que “[...] a recomendação de encadernar os exemplares pressupõe também uma forma posterior de colecionar, conservar e dispor o material, bem como lhe atribuir um caráter similar ao livro e facilitar a consulta e busca de informações [...]", o que, segundo a autora (2001), possibilita ao leitor formar uma idéia mais ampla da proposta editorial do impresso.

\section{O temário da Revista}

Durante o período em que a Revista é veiculada, é possível perceber que ela trabalha fundamentalmente com nove eixos na construção do seu temário. São eles Esportes; Saúde; Alimentação; Fisiologia e treinamento; Fundamentos pedagógicos; Filosofia; Acampamento

Movimento, Porto Alegre, v. 10, n. 3, p.23-52, setembro/dezembro de 2004 
e turismo; Bibliografia e literatura; e Outros. Para se chegar a esse número, foi necessário produzir o temário sobre o que foi veiculado na Revista do número 65 (1942) ao número 88 (1945), já que, do primeiro número lançado (1932) até o número 64 (1942) esse trabalho foi realizado pelos editores do impresso, conforme se apresenta no Quadro l a seguir.

Quadro 1. Temário da revista Educação Physica publicado entre 1932 e $1942^{19}$

O PRIMEIRO DECÊNIO DE "EDUCAÇÃO FÍSICA"

Para que nossos leitores tenham uma idéia do que foi o trabalho produzido pela revista "Educação Física" nesses dez anos de atividade que se comemora com esse número, damos abaixo um resumo numérico das publicações feitas sobre assuntos do seu programa, isto é, educação integral tendo como base a educação física; esses trabalhos se referem aos 64 números até agora publicados:

$\begin{array}{lr}\text { Alimentação } & 192 \\ \text { Atletismo } & 220 \\ \text { Automobilismo } & 12 \\ \text { Basquetebol } & 192 \\ \text { Biografias } & 22 \\ \text { Box } & 34 \\ \text { Ciclismo } & 32 \\ \text { Consultas } & 240 \\ \text { Curiosidades } & 42 \\ \text { Danças } & 24 \\ \text { Diversos } & 320 \\ \text { Doutrina } & 72 \\ \text { Educação Física } & 256\end{array}$

190 Quadro 1 foi veiculado na Revista número 64 (1942, p 48).

Movimento, Porto Alegre, v. 10, n. 3, p.23-52, setembro/dezembro de 2004 
38 Em foco

Omar Schneider e Amarílio Ferreira Neto

\begin{tabular}{|c|c|}
\hline Educação moral & 49 \\
\hline Educação intelectual & 20 \\
\hline Excursionismo & 26 \\
\hline Esgrima & 10 \\
\hline Filosofia & 64 \\
\hline Futebol & 138 \\
\hline Golf & 10 \\
\hline Hand-ball & 10 \\
\hline Higiene & 96 \\
\hline História & 30 \\
\hline Humorismo esportivo & 68 \\
\hline Instruções várias & 120 \\
\hline Jogos esportivos & 68 \\
\hline Lições de ginástica & 78 \\
\hline Literatura & 26 \\
\hline Lutas & 36 \\
\hline Medicina esportiva & 30 \\
\hline Natação & 89 \\
\hline Olimpismo & 36 \\
\hline Pólo aquático & 18 \\
\hline Rúgbi & 10 \\
\hline Saude & 192 \\
\hline Tenis & 68 \\
\hline Voleibol & 39 \\
\hline Yachting & 10 \\
\hline
\end{tabular}

Movimento, Porto Alegre, v. 10, n. 3, p.23-52, setembro/dezembro de 2004 
Como vemos é um total de 3.099 trabalhos sobre educação física, moral e intelectual e assuntos correlatos, a mais completa enciclopédia especializada em idioma brasileiro, reunindo o que de mais moderno sobre o assunto foi publicado no mundo inteiro nesses últimos tempos. E, fazendo um pouco de estatística, bem do gosto norte-americano, esses 3.099 trabalhos representam 10 grossos volumes, num total de 5.336 páginas com cerca de 2.560 palavras as quais o leitor que dedicasse 6 horas por dia à sua leitura, levaria um mês para lê-la sem folgar aos domingos...

O modelo de enciclopédia que o impresso assume, para os editores, facilitaria o manuseio da Revista pelo usuário. A mesma regra foi utilizada anteriormente para produzir o Índice geral das matérias publicadas, o que tornaria mais fácil para o leitor, depois de encadernar, recuperar as informações por meio de verbetes, categoria que os títulos passam a assumir ao agrupar as matérias que se relacionavam com o mesmo assunto.

Para a produção do temário do número 65 (1942) ao número 88 (1945), conforme o Quadro 2, se buscou-se seguir a mesma lógica que os editores utilizaram para organizar a Revista, ou seja a utilização dos títulos em que eram distribuídas as matérias no índice do periódico

Quadro 2. Temário da revista Educação Physica publicado entre 1942 e $1945^{20}$

\begin{tabular}{|ll|}
\hline Alimentação & 26 \\
Fisiologia & 2 \\
Atletismo & 38 \\
Fisiologia aplicada & 2 \\
Basquetebol & 11 \\
Fisioterapia & 2 \\
Bibliografia & 2 \\
Futebol & 5 \\
Biografia & 1 \\
\hline
\end{tabular}

20 Os exemplares número 74, 75, 76 e 83 não tiveram suas matérias divididas por temáticas. Assim, foi necessário apropriar da lógica dos editores e classificar as matérias para que fizessem parte do temário do impresso. Já os números 81 e 82 nem sumários possuíram, por isso foi necessário ler as matérias, classificá-las como pertencente a esse ou aquele título e depois produzir o sumário para, desse modo, incluí-las na feitura do Quadro 2.

Movimento, Porto Alegre, v. 10, n. 3, p.23-52, setembro/dezembro de 2004 


\begin{tabular}{|ll|}
\hline História & 9 \\
Biologia aplicada & 3 \\
História da Educação Física & 4 \\
Biometria & 2 \\
Histórico de nossos clubes desportivos & 2 \\
Bolsas escolares & 2 \\
Instalações desportivas & 1 \\
Campismo & 3 \\
Intoxicação & 1 \\
Ciclismo & 1 \\
Legislação & 5 \\
Clubes & 2 \\
Lutadores & 1 \\
Colônias de férias & 1 \\
Massagem & 1 \\
Consultas & 169 \\
Medicina esportiva & 1 \\
Corredores & 1 \\
Natação & 7 \\
Danças & 1 \\
Olimpismo & 2 \\
Desportos & 1 \\
\hline
\end{tabular}

Movimento, Porto Alegre, v. 10, n. 3, p.23-52, setembro/dezembro de 2004 


\begin{tabular}{|ll|}
\hline Peteca & 1 \\
Diversos & 127 \\
Piscinas & 1 \\
Doutrina & 48 \\
Puericultura & 4 \\
Educação & 4 \\
Pugilismo & 4 \\
Educação Física & 49 \\
Recreação & 1 \\
Educação moral & 27 \\
Higiene & 1 \\
Escotismo & 1 \\
Rugby & 1 \\
Esgrima & 1 \\
Saúde & 1 \\
Estádios & 1 \\
Tênis & 2 \\
Estradasofia de ferro Central do Brasil & 1 \\
Turismo & 38 \\
Excursionismo & 1 \\
\hline
\end{tabular}

Movimento, Porto Alegre, v. 10, n. 3, p.23-52, setembro/dezembro de 2004 
As 3.768 matérias que são veiculadas durante os treze anos em que o impresso é publicado puderam ser classificadas a partir dos títulos em que são agrupadas no Índice do impresso. Ao organizar os dois temários, pôde-se constatar a existência de nove eixos estruturando o projeto editorial do impresso. A Figura 2, a seguir, exemplifica em porcentagem os eixos mais recorrentes no impresso.

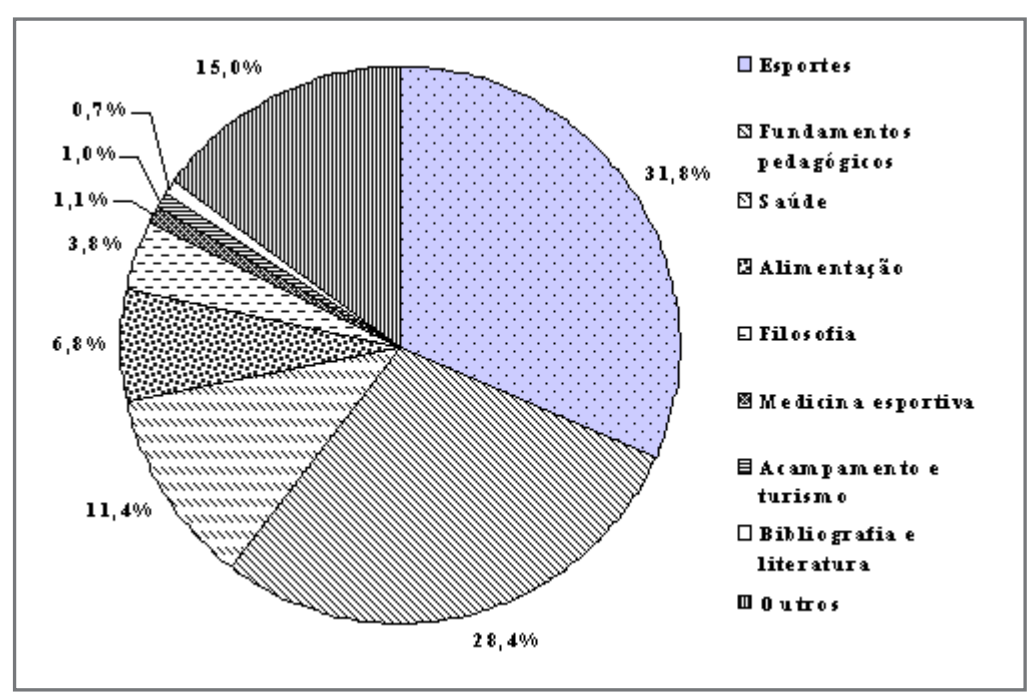

Figura 2. Eixos temáticos da revista Educação Physica (1932-1945)

Em Esportes, estão agrupados todos os títulos que tinham como preocupação vulgarizar algum tipo de manifestação esportiva, regras, técnicas e aconselhamentos sobre como praticar alguma atividade.

Nos que versavam sobre Saúde, por basicamente direcionarem discussões sobre os mesmos assuntos, como: higiene, puericultura e aconselhamentos sobre como adquirir e manter a beleza corporal, os títulos foram agrupados sob o mesmo eixo.

O eixo Alimentação, mesmo estando próximo ao tema saúde, tem sua especificidade, uma vez que os aconselhamentos são em relação a como bem aproveitar os alimentos e preparação de cardápios para atletas e desportistas em geral.

Em Fisiologia e treinamento, estão organizados os títulos que, de alguma maneira, tratam de questões sobre medicina esportiva e

Movimento, Porto Alegre, v. 10, n. 3, p.23-52, setembro/dezembro de 2004 
outros que se relacionavam com a "ciência fisiológica", que forneciam sustentação aos procedimentos referentes ao treinamento.

No eixo Fundamentos pedagógicos, foram agrupados os títulos que tinham como objetivo veicular conhecimentos direcionados para leitores que estivessem envolvidos com a atividade docente. Desse modo, pode-se perceber que estão lá organizados os títulos que visavam a persuadir o professor para o uso de um tipo de esporte, ginástica, aparelho, sistema de medição do desenvolvimento do aluno, assim como aconselhamentos sobre como bem conduzir suas aulas, a História da Educação Física, uma filosofia da Educação Física, a legislação que regulava a profissão, enfim conhecimentos que serviriam como referência para o professor de Educação Física planejar ou executar suas aulas.

O conjunto de matérias denominadas pelos editores da Revista como Filosofia nada mais são do que aforismos, máximas ou sentenças de conteúdo moral, ditados, que buscavam informar aos leitores, mesmo de forma fragmentada, o pensamento de um autor sobre alguma temática relacionada como o corpo, a saúde, a moral, a ética o patriotismo, etc. Os fragmentos publicados, em sua grande maioria, são de clássicos, como Platão, Aristóteles, Séneca, mas também havia a utilização de pensadores modernos, como Voltaire, Victor Hugo, Abraham Lincoln, entre outros. Em uma página, poderia vir até dez pequenas sentenças curtas, que, em sua maioria, eram de autores diferentes, mas todas tinham um ponto que as aproximavam, eram princípios de natureza prática e moral que buscavam aconselhar os leitores sobre as regras do bem viver. Geralmente as matérias que eram impressas sob o título Filosofia vinham na última página do periódico.

Em Acampamento e turismo, estão elencados os títulos que agrupavam as matérias que versavam sobre excursionismo, agenda de viagens, colônias de férias e escotismo. Já no eixo Bibliografia e literatura estão incluídas as matérias que buscavam orientar os leitores para a leitura de algum livro, ou faziam comentários de livros sobre Educação Física e esporte, na maioria das vezes pertencentes à própria editora que publicava o impresso.

No eixo Outros, foram agrupados os títulos que não eram possíveis de serem incluídos em nenhum dos eixos anteriormente citados. As matérias que foram veiculadas sob os títulos (Diversos e Instruções várias) que compõem o eixo Outros, como a designaç̧ão delas deixa claro, eram matérias que não cabiam nos outros eixos,

Movimento, Porto Alegre, v. 10, n. 3, p.23-52, setembro/dezembro de 2004 
por isso o nome dos títulos antecipadamente informa aos leitores sobre a diversidade das matérias reunidas sob tais títulos.

Como se pode observar, para compor a Revista e dar forma ao seu projeto editorial, o assunto mais discutido foi o Esporte, com 31,8\% de recorrência. Ele funcionou como um dos eixos norteadores da publicação e sobre ele uma ampla gama de saberes circularam, tanto relacionados com os fundamentos das atividades esportivas, quanto em relação à preparação técnica, treinamento e regramento para realizar certas atividades. Em segundo lugar, e não menos importante, estão os títulos que buscavam discutir os Fundamentos pedagógicos da Educação Física. Somados, eles atingiram $28,4 \%$ do material veiculado nos 88 exemplares da Revista. Nesse eixo temático, estão dispostas as matérias que versavam sobre o bom desempenho dos professores, modelos de aulas e as seções de consultas em que os leitores tinham suas dúvidas respondidas por um dos editores do impresso.

Como um dos objetivos projetados para o impresso era a melhoria/aperfeiçoamentos da juventude brasileira, como afirmavam os editores, muitas matérias foram alvo dessa preocupação, chegando a ser o terceiro tema da linha editorial do periódico. Os aconselhamentos sobre Saúde obtiveram 11,4\% de recorrências na catalogação, mas possivelmente pode ser maior, uma vez que mesmo a vulgarização dos esportes era prevista pelos editores como uma forma de aperfeiçoamento da raça. Para os editores, como se pode perceber no programa que veiculam do primeiro ao último número, a prática de esportes ou a adoção de um sistema de exercícios eram vistas como um meio de promover a saúde e, conseqüentemente, a melhoria da raça.

Dos eixos que compõem a fórmula editorial da Revista e fazem com que seja projetada como enciclopédia, as prescrições sobre os esportes, sobre os fundamentos pedagógicos da Educação Física e sobre as questões relacionadas com os aconselhamentos sobre saúde são as que mais permitem que ela chame a atenção dos leitores e dos investidores que passam a veicular seus produtos e serviços em suas páginas. Como um periódico que tenta ser projetado para não ser efêmero, que se lê e descarta, os editores buscam produzir uma outra relação do público com a Revista. Ele é material para se ler, encadernar e guardar, sendo essa uma das principais estratégias colocadas em circulação pelos editores. Uma vez que assume um outro suporte, o impresso

Movimento, Porto Alegre, v. 10, n. 3, p.23-52, setembro/dezembro de 2004 
adquire outras características e passa a manter uma outra relação com os leitores.

\section{Produtos e publicidade: forma e sentido em movimento}

Por ser um impresso editado por uma editora comercial, a revista Educação Physica, no período em que circula, assume várias funções. Ao mesmo tempo em que se apresenta como uma leitura informativa e recreativa para seus compradores, ela faz veicular matérias sobre os conhecimentos necessários aos professores de Educação Física. Outra função atribuída à Revista é a de ser um estande, local em que se expõem variados produtos e serviços ao público leitor. A Revista já nasce com essas características, mas, durante os anos, ela vai sendo paulatinamente sofisticada.

Os produtos e serviços oferecidos por meio do impresso abrangem uma gama muito grande de materiais, alguns com ligação direta com a proposta da Revista, mas outros em que não se percebe relação imediata, a não ser a que é construída pelos editores ao vincular determinado produto e serviço à melhoria da saúde, ao desenvolvimento da beleza física, ao ganho de força e ao melhoramento das características raciais.

A fórmula editorial empregada pela Revista permite anunciar a venda e a locação de imóveis, lojas de compra e aluguel de roupas, chapéus, calçados, eletrodomésticos, remédios contra várias infecções, aulas de canto e preparação profissional, assim como publicar anúncios profissionais de diversas áreas, como professores particulares e médicos. Também empresas seguradoras, de transporte, de lavanderia, de remédios, de móveis, de câmbio, de alimentação, de tipografia, livrarias e instituições de ensino anunciam no impresso. Além desses produtos e serviços, a Revista oferece para seus leitores muitas outras mercadorias: são tônicos para aumentar a força e a disposição, materiais esportivos, como roupas e calçados para a prática de ginástica e esportes, alimentos para desportistas, leituras sobre a Educação Física, esportes e saúde e escolas particulares.

Com o objetivo de auxiliar os leitores a consultarem o periódico, a partir da publicação do segundo número, começa-se a publicar um dispositivo editorial chamado: Índice dos Annuncios. É um segundo sumário da Revista. Nele estão dispostos, em ordem alfabética, o local em que o leitor encontrará determinado produto no interior da Revista. Do mesmo modo que o Índice das matérias,

Movimento, Porto Alegre, v. 10, n. 3, p.23-52, setembro/dezembro de 2004 
esse dispositivo nasce com a finalidade de didatizar a Revista, fazer com que o leitor realize o menor esforço possível para compreender a lógica do impresso e, mesmo assim, dele pudesse tirar o maior proveito possível.

Para os anunciantes, o recurso do Índice dos Annuncios é muito conveniente, pois faz com que seus produtos ganhem maior visibilidade, porquanto são apresentados aos leitores de duas maneiras, uma ao folhear aleatório das páginas do impresso e o encontro casual com o material que é oferecido e outra por meio de um índice alfabético das mercadorias que são oferecidas no interior do periódico.

Perceber a Revista nessas condições faz com que se compreenda que ela exerce dois papéis: um é o de oferecer aos leitores informações sobre as atividades esportivas no Brasil e no mundo, discussões sobre saúde e prescrições sobre a atuação do professor dentro e fora da escola; o outro papel desempenhado pelo impresso relaciona-se com sua semelhança com um catálogo de vendas de produtos, tanto referentes à Educação Física e esportes, quanto a produtos que com essas atividades não mantêm relação aparente. A fórmula que empregam sustenta essa dupla relação com os leitores. Informar e vender torna-se o pilar que mantém a Revista circulando.

Em algumas Revistas, não foi impresso o índice, mas isso não quer dizer que não houve publicação de propagandas; houve sim a sua diminuição, como no ano de 1933 e nos anos finais de sua circulação.

Conforme os editores da revista Educação Physica, o impresso é direcionado a um público específico. Em primeiro lugar, projetase como principal consumidor os professores e técnicos de Educação Física, diretores de colégios, médicos, alunos de cursos de Educação Física e pais de família, mas, pelo tipo de temática que aborda, a Revista tem potencial para chamar a atenção de um público muito maior de leitores. Assim, nas palavras dos editores, ela tem como meta atingir "[...] a todos enfim, que se interessam pela sua própria saúde, pela conservação de suas qualidades física [sic] desenvolvidas pelo aperfeiçoamento de suas qualidades morais" (EDUCAÇÃO PHYSICA, 1940, n. 38, p. 80, grifo do autor).

Ao ter como pano de fundo a veiculação de questões ligadas ao tema saúde, desenvolvimento físico e aperfeiçoamento moral, o impresso torna-se apropriado para o oferecimento de produtos que estejam relacionados com o cultivo do corpo. Mesmo produtos

Movimento, Porto Alegre, v. 10, n. 3, p.23-52, setembro/dezembro de 2004 
que não estejam diretamente ligados a essas atividades são atraídos para o impresso, pois, de maneira geral, os produtos passam a ser associados à imagem que a Revista quer produzir. Desse modo, as mercadorias veiculadas passam a ser integradas ao contexto do periódico e a compartilhar das representações que ela produz. Em função desse tipo de associação que poderia ser feita, quando o projeto completa doze anos de existência, os editores fazem a seguinte observação:

[...] doze anos de esforços, de lutas contínuas, de verdadeiros sacrifícios para realizaro programa a que se havia proposto. Sem qualquer apôio oficial, mantendose à custa própria, cobrindo as suas despesas com o produto da publicidade selecionada que exigia - regeitando [sic] sempre anúncios de emprêsas que atentavam contra a economia popular ou que encobriam fins pouco patrióticoscom as assinaturas e venda avulsa que os milhares de leitores sempre lhe asseguraram [...] (EDUCAÇÃO FÍSICA, 1944, n. 79-80, p. 5).

O artifício de associar produtos não necessariamente aplicáveis, ou fáceis de se contextualizar, ao mundo da Educação Física, esportes e saúde pode ser exemplificado pela série de matérias patrocinadas pela companhia de lâminas de barbear Gillette.

Nas matérias patrocinadas pela Gillette, são apresentadas aos leitores gravuras de homens e mulheres praticando esportes, em grupo ou individualmente, um roteiro de exercícios, segundo a atividade que se apresenta, uma explicação sobre o sentido ou história do esporte ou ginástica e um texto em que se associa o produto à Educação Física/atividade esportiva.

Em uma propaganda realizada da empresa de lâminas de barbear Gillette, após apresentar a gravura de um praticante de medicinebol e as informações de como tal atividade deveria ser realizada os editores completam a prescrição, associando a seguinte mensagem à imagem.

Conforme indica o seu nome, este moderno sport utiliza a bola como exercício para a conquista da saúde e vigôr. Experiência recentes revelaram-seo 'medicine ball' um excellente meio de curar varias enfermidades do apparelho digestivo e do systema nervoso. É um exercicio util, recreativo e hygienico, sem a monotonia da gymnastica commum. Além disso, é eminentemente social, pois constitue um optimo motivo para reunir amigos. A mesma finalidade de saúde e hygiene tem o methodo Gillette de barbear em casa, sem a monotonia dos velhos systemas e tambem com um fim social, queéo de proporcionar aos homens uma apparencia que a todos agrada. Passe a fazer sua barba diariamente, em casa. Adquira um apparelho Gillette e use-o sempre com laminas Gillette Azul, as únicas rigorosamente asepticas. Terá dado um grande passo para a defesa de seu rosto 
contra perigosas infecções (EDUCAÇÃO FÍSICA, 1940, n. 46, p. 50).

A fórmula editorial da revista Educação Physica permite esse tipo de associação, pois os três eixos nos quais ela se fundamenta: Educação Física, esporte e saúde têm como ponto de apoio as discussões relacionadas com a higiene, a moral e a beleza. Desse modo, quando se anuncia algum produto ou serviço na Revista, esses são associados aos ideais que o impresso faz circular.

Conforme Barzotto (1998, p. 45), a forma define os espaços de leitura e os próprios leitores, “[...] ou seja, a revista instruirá os leitores a manuseá-la e a lê-la, visando integrá-los no grupo de leitores pertinentes para o momento". Indo além das assertivas do autor, pode-se dizer que a fórmula que o impresso assume faz com que o leitor seja conduzido a perceber os produtos e serviços oferecidos de acordo com a concepção em que o projeto se movimenta.

Na produção da fórmula editorial, os editores colocam em ação um conjunto de dispositivos com a intenção de instruir os leitores a um bom uso do periódico. Alguns dos recursos de composição utilizados já eram empregados no mundo dos impressos, mas, nesse processo, também conseguiram inovar, como no caso dos Índices dos Annuncios. Funcionando como um mapa de manuseio da Revista, tal dispositivo integra o seu aparelho crítico e, assim como os outros dispositivos, capa, índice das matérias e índice geral das matérias publicadas, faz parte da estratégia editorial do impresso.

\section{Considerações finais}

Os dispositivos que são empregados na composição da fórmula editorial da revista Educação Physica possuem como objetivo facilitar não só o manuseio e uso do impresso, mas também têm como objetivo fazer com que o leitor passe a compreender o periódico realmente como um repertório, no qual se poderia ter acesso de forma ordenada aos conhecimentos necessários à docência ou às atividades esportivas.

O modo de manipulação proposto para a Revista era que essa efetivamente fosse utilizada como uma enciclopédia, uma ferramenta para ser usada no cotidiano, lugar em que o professor ou o interessado 
nas questões relacionadas com a Educação Física, os esportes ou a saúde teriam acesso rápido a conhecimentos sistematizados de forma metódica.

O impresso mantém-se na conjunção de duas propostas, uma de destinação pedagógica e outra comercial. Trabalhando nessa conjunção, ele abriu condições para atender a dois tipos de público, um composto por professores que buscavam se atualizar com leituras sobre a atividade docente e outro formado por entusiastas do esporte, ávidos por notícias sobre a vida esportiva no Brasil e no mundo, utilizando o periódico mais como leitura informativa e de passatempo. Não obstante, buscarem arregimentar um público específico, que são os professores e técnicos de Educação Física, os diretores dos colégios, os médicos e os alunos dos cursos de formação de professores. Os editores do impresso deixam claro que o periódico era para todos que “[...] se interessam pela sua própria saúde, pela conservação de suas qualidades física [sic] desenvolvidas pelo aperfeiçoamento de suas qualidades morais" (REVISTA EDUCAÇÃO PHYSICA, 1940$, n. 38, p. 80$)$.

O sentido produzido para a coleção das revistas, quando encadernadas e postas lado a lado, era o de materializar a idéia de uma enciclopédia. Mesmo a possibilidade de os impressos poderem ser armazenados na posição vertical e não na posição horizontal, como costumeiramente se guarda a publicação periódica produzida no formato brochura, indicia os modos de manipulação propostos para a Revista. O periódico passou a se constituir em uma enciclopédia, deixando de ser percebido como uma leitura apenas de passatempo e sendo visto como um objeto que poderia ser lido, encadernado e posto em uma estante, transformando-se, assim, em referência para consulta, tiradúvidas, receituário e para pesquisas que se relacionassem com os esportes, os fundamentos pedagógicos da Educação Física e as prescrições sobre a obtenção e manutenção da saúde, sendo esses os três principais eixos que os editores desenvolvem para chamar a atenção dos leitores para a aquisição e assinatura do impresso.

Ao observar os Quadro l e 2, pode-se verificar que, no rol de atividades que os editores apresentam aos leitores, muitas não são comuns ao que entendemos hoje como conteúdos a serem tratados pela Educação Física. O temário com o qual lidavam os professores de Educação Física era bem mais amplo. Suas leituras

Movimento, Porto Alegre, v. 10, n. 3, p.23-52, setembro/dezembro de 2004 
envolviam temas como: yachting, automobilismo, golf, rúgbi, tênis, esgrima, excursionismo, box, pólo aquático etc.

A Revista apresenta-se como um bom panorama esportivo das décadas de 1930 e 1940 no Brasil e dos temas que animavam as discussões sobre os conteúdos a serem tratados pela Educação Física e o lugar dessa disciplina no cenário educacional, o que deixa ver que, no processo de institucionalização da Educação Física como disciplina escolar, muitos saberes foram sendo adicionados ao rol de conhecimentos tidos como necessários à atuação docente, assim como outros foram sendo interditados e progressivamente deslegitimados como temas a serem apreendidos/ensinados pelo professor. Exemplo desse fato é o processo de esportivização da Educação Física, no qual a ginástica passa a ser deixada em segundo plano, em favor de uma maior racionalização e controle do movimento humano. ${ }^{21}$ Processo que se pode flagrar com base na leitura do discurso veiculado pela revista de Educação Physica, mas que também pode ser percebido de forma quantitativa, quando se observam os eixos temáticos mais privilegiados pelos editores na composição da estratégia editorial do impresso.

Existe a necessidade de se compreender a palavra impressa não apenas como registro do que aconteceu, mas como parte constituinte do acontecimento, como uma força ativa na história que registra ao mesmo tempo em que produz novas culturas, local em que se pode perceber a disputa entre o velho e o novo, em que bens culturais são produzidos, feitos veicular e apropriados.

Estrategias editoriales, enciclopedismo, productos y
publicidad en la revista Educação Physica (1932-1945)
Resumen: Discute la fórmula editorial de la revista
Educação Physica, periódico sobre Educación Física,
deportes y salud que circuló desde los años 1932 hasta
1945, en la ciudad de Rio de Janeiro. Analiza el producto
crítico de lo impreso, prestando atención a los disposi-
tivos editoriales empleados por los editores para mayor
control sobre los modos de manipulación y usos de la
Revista. Aborda el periódico como enciclopedia y el
estándar de productos y publicidad.
Palabras - claves: Revista Educação Physica, Dispo-
sitivos, Fórmula Editorial.

21 Sobre o tema da esportivização da Educação, Física ver o texto publicado por Schneider (2004), na Revista Brasileira de Ciências do Esporte, v. 25, n. 2, com o
título Entre a correção e a eficiência: mutações no significado da Educação Física nas décadas de 1930 e 1940: um estudo a partir da revista Educação Physica.

Movimento, Porto Alegre, v. 10, n. 3, p.23-52, setembro/dezembro de 2004 


\begin{abstract}
Editorial strategies, encyclopedic knowledge, products and publicity in the "Educação Physica" magazine (1932 - 1945)

Abstract: It discusses the "Educação Physica" magazine editorial fomula, Ihe periodical is about Physical Education, sports and health, circulated among 1932 and 1945, in Rio de Janeiro City. It analyzes Ihe critical instrument of lhe magazine, paying attention to lhe editorial gadgets which are used by publishers for a better control of manipulation and uses of Ihe magazine. Its approach is Ihe periodical as an encyclopedia and a stall for products and publicity.

Keywords: "Educação Physica" Magazine, Gadgets, Editorial Formula.
\end{abstract}

\title{
Referências
}

A EDUCAÇÃO física: já se acha à venda a coleção de 1938. Educação Física Rio de Janeiro, n. 38, p. 76, jan. 1940.

ANDRADE, Olímpio de Souza. O livro brasileiro: desde 1920. Rio de Janeiro: Livraria e Editora Cátedra, 1978.

BARBOSA, Rui. Conceito e importância da educação física. Educação Física, Rio de Janeiro, n. 44, p. 10-12; 66 e 72-73, jul. 1940.

BARZOTTO, Valdir Heitor. Leituras de revistas periódicas: forma, texto e discurso: um estudo sobre a revista Realidade (1966-1967). 1998. 228 f. Tese (Doutorado em Lingüística) - Instituto de Estudos da Linguagem, Universidade Estadual de Campinas, Campinas, 1998.

BICCAS, Maurilane de Souza. O impresso como estratégia de formação de professores(as) e de conformação do campo pedagógico em Mina Gerais: o caso da revista do ensino (1925-1940). 2001. 311 f. Tese (Doutorado em História da Educação e Historiografia) - Programa de Pós-Graduação em Educação, Universidade de São Paulo, São Paulo, 2001.

CHARTIER, Roger. Leituras e leitores na França do antigo regime. São Paulo: Editora Unesp, 2004

. A história cultural: entre práticas e representações. Lisboa: Difel, 1990.

O mundo como representação. Estudos Avançados: Instituto de Estudos Avançados - USP, São Paulo, v. 5, n. 11, p. 173-191, abr. 1991.

A ordem dos livros: leitores, autores e bibliotecas na Europa entre os séculos XIV e XVIII. Brasília: Editora da Universidade de Brasília, 1994.

HALLEWELL, Laurence. O livro no Brasil: sua história. São Paulo: Edusp, 1985. DOZE anos de luta e perseverança. Educação Física, Rio de Janeiro, n. 79-80, p. 5, maio/jun. 1944.

POLK, Ralfh W. Manual do tipógrafo. São Paulo: Edições LEP Ltda. 1948.

Movimento, Porto Alegre, v. 10, n. 3, p.23-52, setembro/dezembro de 2004 
MAURíCIO, Hélio Vecchio. A educação física e suas vantagens. Educação Física, Rio de Janeiro, n. 48, p. 31-32 e 64, nov. 1940.

NUNES, Clarice. História da educação brasileira: novas abordagens de velhos objetos. Teoria e Educação, Panorâmica, Porto Alegre, n. 6, p. 151-182, 1992. NUNES, Clarice; CARVALHO, Marta Maria Chagas de. Historiografia da educação e fontes. Cadernos da ANPED, Belo Horizonte, n. 5, p. 7-64, set. 1993.

PARA ser um bom professor de Educação Física. Educação Física, Rio de Janeiro, n. 72, p. 6, jan./fev. 1943.

SCHNAPP, Alain. A arqueologia. In: LE GOFF, Jacques; NORA Pierre (Org.). História: novas abordagens. Rio de Janeiro: Francisco Alves, 1988. p. 1- 20.

SCHNEIDER, Omar. A revista Educação Physica (1930-1940): estratégias editoriais e prescrições educacionais. 2003. $342 \mathrm{f}$. Dissertação (Mestrado em Educação) - Programa de Estudos Pós-Graduados em Educação: História, Política, Sociedade, da Pontifícia Universidade Católica de São Paulo, São Paulo, 2003

Entre a correção e a eficiência: mutações no significado da Educação Física nas décadas de 1930 e 1940: um estudo a partir da revista Educação Physica. Revista Brasileira de Ciências do Esporte, Florianópolis - SC, v. 25, n. 2, p. $39-54,2004$.

SPORT - factor de saúde: medicine ball. Educação Física, Rio de Janeiro, n. 46, p. 50 , set. 1940 .

TOLEDO, Maria Rita de Almeida. Coleção atualidades pedagógicas: do projeto político ao projeto editorial (1931-1981). 2001. 295 f. Tese (Doutorado em Educação) - Programa de Pós-Graduação em Educação: História e Filosofia da Educação, Pontifícia Universidade Católica de São Paulo, São Paulo, 2001

Recebido em: 12/10/2004

Aprovado em:12/11/2004

Omar Schneider Rua José Dias de Oliveira, nº 895 Bairro Vila Fonseca, Aimorés - Minas Gerais CEP.: 35200-000 omaratom@hotmail.com

Amarílio Ferreira Neto

Caixa Postal: 019030 ACF - Campus Universitário Vitória - Espírito Santo CEP.: 29075-973

amarílio@proteoria.org

Movimento, Porto Alegre, v. 10, n. 3, p.23-52, setembro/dezembro de 2004 